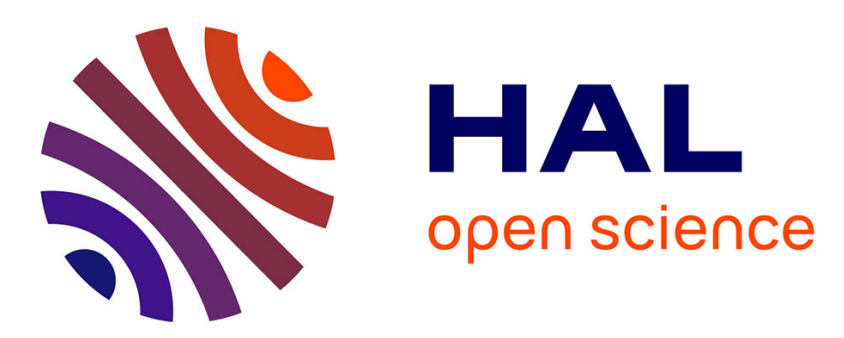

\title{
DIFFUSE X-RAY SCATTERING NEAR SMECTIC C-NEMATIC PHASE TRANSITION TEMPERATURE
}

\author{
H. Terauchi
}

\section{To cite this version:}

H. Terauchi. DIFFUSE X-RAY SCATTERING NEAR SMECTIC C-NEMATIC PHASE TRANSITION TEMPERATURE. Journal de Physique Colloques, 1979, 40 (C3), pp.C3-401-C3-403. 10.1051/jphyscol:1979380 . jpa-00218776

\section{HAL Id: jpa-00218776 https://hal.science/jpa-00218776}

Submitted on 1 Jan 1979

HAL is a multi-disciplinary open access archive for the deposit and dissemination of scientific research documents, whether they are published or not. The documents may come from teaching and research institutions in France or abroad, or from public or private research centers.
L'archive ouverte pluridisciplinaire HAL, est destinée au dépôt et à la diffusion de documents scientifiques de niveau recherche, publiés ou non, émanant des établissements d'enseignement et de recherche français ou étrangers, des laboratoires publics ou privés. 


\title{
DIFFUSE X-RAY SCATTERING NEAR SMECTIC C-NEMATIC PHASE TRANSITION TEMPERATURE
}

\author{
H. TERAUCHI \\ Department of Physics, Kwansei Gakuin University, Nishinomiya, 662, Japan
}

\begin{abstract}
Résumé. - Nous avons pour but d'élucider la nature de la transition de phase en examinant avec précision la diffusion critique de rayons $X$ tirée de 4,4'-Bis(heptyloxy)azoxybenzène $\mathrm{C}_{26} \mathrm{H}_{38} \mathrm{~N}_{2} \mathrm{O}_{3}(\mathrm{HAB})$ près de la température de transition smectique C-nématique.

Abstract. - X-ray critical scattering from 4,4'-Bis(heptyloxy)azoxybenzene $\mathrm{C}_{26} \mathrm{H}_{38} \mathrm{~N}_{2} \mathrm{O}_{3}(\mathrm{HAB})$ near the smectic $C$-nematic phase transition temperature is carefully examined to clarify the nature of the phase transition.
\end{abstract}

1. Introduction. - Recently, many attempts have been made to elucidate the nature of molecular interactions in the liquid crystals. The X-Ray scattering technique is also a good tool to clarify the nature. The intensity of X-Ray scattering intensity from liquid crystals is observed at a following scattering angle $2 \theta$ [1] :

1. Small angle scattering near $2 \theta \cong 0^{\circ}$,

2. Bragg scattering from smectic liquid crystals near $2 \theta \cong 4^{\circ}$,

3. Halo scattering near $2 \theta \cong 20^{\circ}$, when $\mathrm{CuK} \alpha_{1}$ radiation is employed.

Here we report the results of case 2 in 4, 4'-Bis(heptyloxy)azooxybenzene, $\mathrm{C}_{26} \mathrm{H}_{38} \mathrm{~N}_{2} \mathrm{O}_{3}$ (HAB). Espesially, the diffuse $\mathrm{X}$-Ray scattering above the smectic C-nematic phase transition temperature $\left(T_{\mathrm{c}}=93^{\circ} \mathrm{C}\right)$ is carefully examined to clarify the mechanism of the phase transition. Preliminary results of the diffuse scattering from $\mathrm{HAB}$ are given in reference [4]. The extended study of this substance is carried out and some new aspects of the phase transition as given in the next section are obtained and discussed on the basis of the Landau theory [2].

2. Experiments. - $\mathrm{CuK} \alpha_{1}$ radiation $(60 \mathrm{kV}$, $100 \mathrm{~mA}$ max.) monochromatized by a flat plate of a graphite crystal was used throughout the measurements. A divergent slit of $0.15 \mathrm{~mm}$ in width was placed at a distance of $165 \mathrm{~mm}$ from the monochromator and two receiving slits of $1 \mathrm{~mm}$ in width were set at a distance of $150 \mathrm{~mm}$ and $190 \mathrm{~mm}$ from the specimen. The intensity of the X-Ray beam scattered by the specimen was measured by a proportional counter. The horizontal resolution obtained by scanning the incident beam around the zero scattering angle was estimated to be $0.06^{\circ}$. The specimen sat in a $2 \mathrm{~mm}$ diam. hole drilled into a $1 \mathrm{~mm}$ thich copper block with $0.01 \mathrm{~mm}$ mylar windows on both sides. The hot stage was set in the $5 \mathrm{~mm}$ gap of a magnet with a field of 100 Oe. The temperature of the specimen was controlled within $\pm 0.05^{\circ} \mathrm{C}$.

The typical intensity profiles observed at $T_{\mathrm{c}}-8^{\circ} \mathrm{C}$ (smectic phase) and $T_{c}+4{ }^{\circ} \mathrm{C}$ (nematic phase) are shown in figure 1, where a small triangle gives a

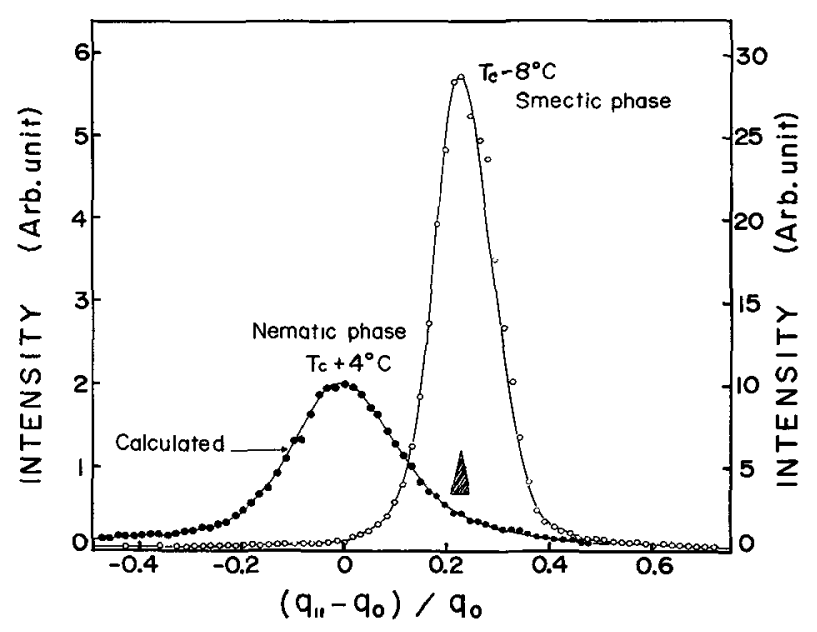

FIG. 1. - Intensity profiles in the smectic $\mathrm{C}$ and nematic phases.

resolution function. The peak intensity in the smectic phase is about 15 times of that in the nematic phase. The peak position of the smectic Bragg scattering shifts from the peak position of the diffuse scattering observed in the nematic phase, indicating that the smectic phase of HAB is a smectic $\mathrm{C}$ and the diffuse scattering comes from a short range ordering of a smectic $\mathrm{A}$. The absolute value of $\mathbf{q}_{0}$ is given by $2 \pi / d$, where $d$ is a spacing of a smectic $\mathrm{A}$ and $\mathbf{q}_{\|}$ 
is the wave vector parallel to the applied magnetic field. The full width at half maximum of the diffuse scattering at $T_{\mathrm{c}}+4^{\circ} \mathrm{C}$ is twice of that of smectic Bragg scattering at $T_{\mathrm{c}}-8{ }^{\circ} \mathrm{C}$.

The peak intensity of the Bragg scattering in the smectic phase is almost constant and drops abruptly at $T_{\mathrm{c}}=93{ }^{\circ} \mathrm{C}$, as given in figure 2 . It is found that the smectic C-nematic phase transition is the first order. Just above $T_{\mathrm{c}}$, the intensity increases due to the shoulder of diffuse scattering in the nematic phase. The intensity of the diffuse scattering above $T_{\mathrm{c}}$ decreases with increasing temperature. In figure 3 , the inversed intensities are plotted as a function of temperature.

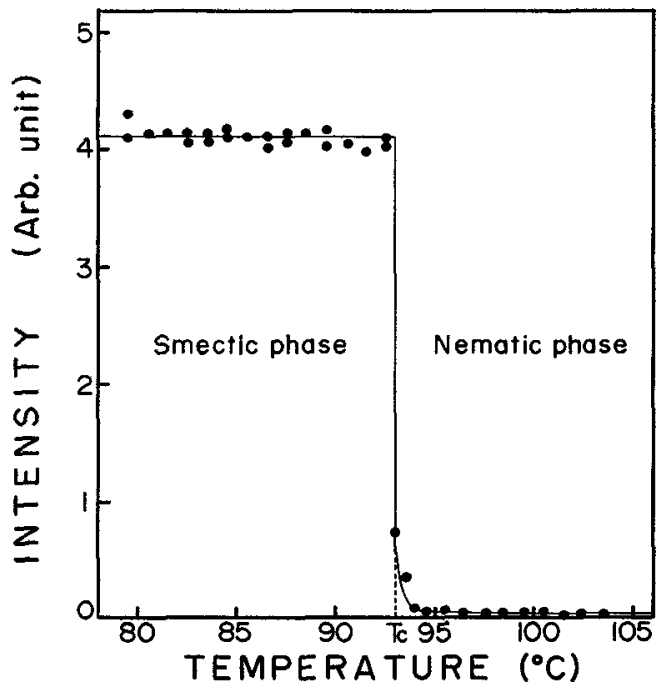

FrG. 2. - Temperature dependence of the Bragg scattering intensity in the smectic $\mathrm{C}$ phase.

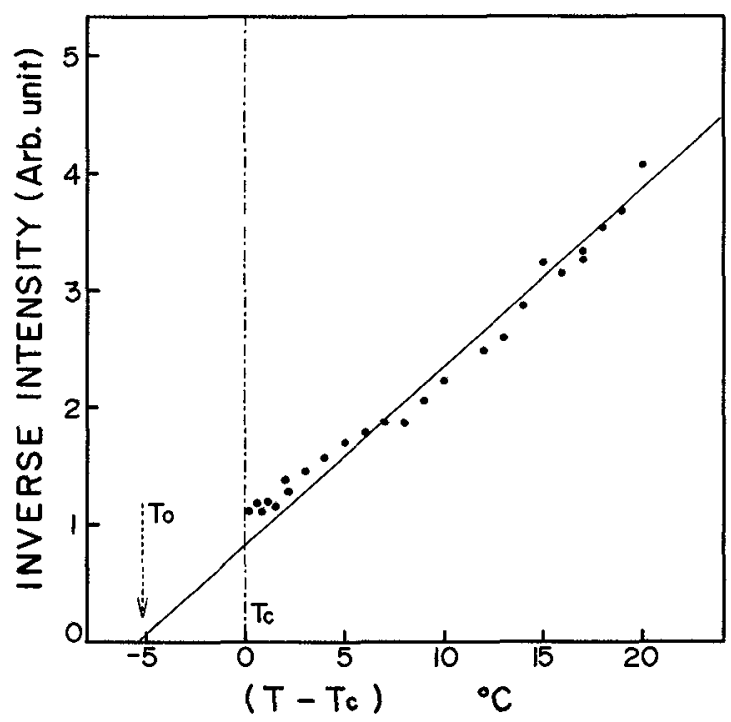

FIG. 3. - Temperature dependence of the reciprocal diffuse intensity in the nematic phase.

The intensity profiles of the diffuse scattering are carefully measured at several temperature in the nematic phase. Some of them are given in reference [4] and it is found that the peak position $q_{o}$ of the diffuse scattering increases with increasing temperature in the nematic phase. In figure 4 , the observed value

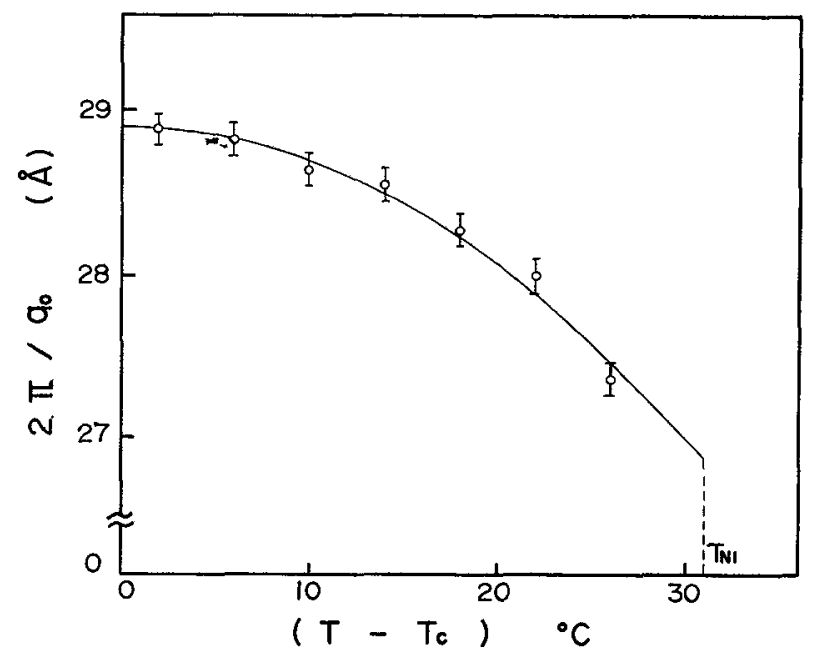

FIG. 4. - Temperature dependence of the average spacing between the smectic layer in the nematic phase.

of $2 \pi /\left|\mathbf{q}_{0}\right|$ is plotted as a function of temperature. The short range ordering of the smectic $A$ in the nematic phase decreases with increasing temperature due to the fluctuation of a director and the average spacing of the smectic A layer decreases with increasing temperature. The temperature dependence of $2 \pi /\left|\mathbf{q}_{0}\right|$ gives the temperature dependence of the order parameter in the nematic phase, that is,

$$
2 \pi /\left|\mathbf{q}_{0}\right| \propto \eta=\left\langle 1 / 2\left(3 \cos ^{2} \theta-1\right)\right\rangle .
$$

The value of $\theta$ is estimated to be about $20^{\circ}$ at the nematic-isotropic phase transition temperature $T_{\mathrm{NI}}=124^{\circ} \mathrm{C}$, if $\theta=0^{\circ}$ at $T_{\mathrm{c}}$.

3. Discussion. - The measurement of X-Ray diffuse scattering from $\mathrm{HAB}$ was carefully carried out above the smectic C-nematic phase transition temperature $T_{\mathrm{c}}$ and it is found that the transition is the first order and the short range ordering of a smectic $\mathrm{A}$ appears in the nematic phase. Following the Landau theory $[2,3]$, the order parameter of a smectic $A$ is a density wave given by

$$
\rho_{\mathbf{r}}=\sum_{\mathbf{q}} \rho_{\mathbf{q}} \mathrm{e}^{\mathbf{i q .} . \mathbf{r}},
$$

and a free energy is written by

$$
F(\mathbf{q}, T)=F_{0}+\frac{1}{2} a(\mathbf{q}, T)\left|\rho_{\mathbf{q}}\right|^{2}+\cdots,
$$


where $F_{0}$ is a energy of no density wave and $a(\mathbf{q}, T)$ has a cylindrical and inversion symmetry in $\mathbf{q}$-space and has a minimum at $\mathbf{q}=\mathbf{q}_{0}$ as following,

$$
\begin{aligned}
a(\mathbf{q}, T)=A(T- & \left.T_{0}\right) / T_{0}+ \\
& +B\left(\mathbf{q}_{\|}-\mathbf{q}_{0}\right)^{2} / \mathbf{q}_{0}^{2}+C \mathbf{q}_{\perp}^{2} / \mathbf{q}_{0}^{2} .
\end{aligned}
$$

Here $\mathbf{q}_{\|}$and $\mathbf{q}_{\perp}$ are the wave vector parallel and perpendicular to the external field direction and also to the normal vector of the smectic plane, $A, B$ and $C$ are constant and $T_{0}$ is a hypothetical transition temperature of a second order phase transition.

The thermodynamical average of mean square amplitude is given by,

$$
\begin{aligned}
\left\langle\rho_{\mathbf{q}}^{2}\right\rangle & =\int \rho_{\mathbf{q}}^{2} \mathrm{e}^{-F / k_{\mathbf{B}} T} \mathrm{~d} \rho_{\mathbf{q}}^{2} / \int \mathrm{e}^{-F / k_{\mathbf{B}} T} \mathrm{~d} \rho_{\mathbf{q}}^{2} \\
& =1 / a(\mathbf{q}, T) .
\end{aligned}
$$

The intensity of diffuse X-Ray scattering is then written by

$$
\begin{aligned}
I_{\mathbf{d}} & =\sum_{\mathbf{r} \mathbf{r}^{\prime}}\left\langle\rho_{\mathbf{r}} \rho_{\mathbf{r}^{\prime}}\right\rangle \mathrm{e}^{i \mathbf{q} \cdot \mathbf{r}-\mathbf{r}^{\prime}} \\
& =\left\langle\rho_{\mathbf{q}}^{2}\right\rangle=1 / a(\mathbf{q}, T) \\
& =\left[A\left(T-T_{0}\right) / T_{0}+B\left(\mathbf{q}_{\|}-\mathbf{q}_{0}\right)^{2} / \mathbf{q}_{0}^{2}+C \mathbf{q}_{\perp}^{2} / \mathbf{q}_{0}^{2}\right]^{-1} .
\end{aligned}
$$

This equation indicates that the diffuse intensity profiles is a two dimensional Lorentzian. The calculated intensity in the $\mathbf{q}_{\|}$direction is shown in figure 1, where $A=1, B=1542, C=0$ and the intensity is normalized at $\boldsymbol{q}_{0}$ and $T_{0}$ is estimated as $T_{0}=T_{\mathrm{c}}-5.1{ }^{\circ} \mathrm{C}$ from the plots of $1 / I_{\mathrm{d}} v s$ tempe- rature given in figure 3. The agreement between the calculated curves and observed values is excellent. A high-resolution X-Ray scattering study of the critical fluctuations in the nematic phase associated with the smectic A-nematic transition in CBOOA was carried out and the new critical index was determined [5]. However our results is more likely to be consistent with the classical Landau's theory.

The new aspects on the smectic $\mathrm{C}$-nematic phase transition at $T_{\mathrm{c}}=93{ }^{\circ} \mathrm{C}$ in $\mathrm{HAB}$ have been obtained in the present work. Especially a short range ordering of a smectic A phase appears in the nematic phase. The temperature dependence of $2 \pi / q_{0}$ implies molecular length changes, or tilting of molecules which decreases gradually with increasing temperature in the nematic phase as shown in figure 4. On the otherhand, the value of $\left|\mathbf{q}_{0}\right|=2 \pi / d$ becomes larger in the smectic phase than $\left|\mathbf{q}_{0}\right|$ in the nematic phase as shown in figure 4. The value of $\mathbf{q}_{0}$ is almost constant in the smectic phase and increases with increasing temperature in the nematic phase in HAB. There is a fairly large jump in the $q_{0}$ value at $T_{c}$ accompanied with the first order phase transition. The study of this material under uniaxial pressure is now progress near $T_{\mathrm{c}}$ in order to clarify the nature of the phase transition, expecting some new phases near $T_{\mathrm{c}}$ and pressure dependences of the $\dot{q}_{0}$ value.

Acknowledgments. - The author wishes to express his thank to Mr. R. Ohnishi for his assistance during the work, and to Professors A. Kawamori, S. Naya, K. Yoshimitsu, C. W. Woo, A. de Vries, R. J. Birgeneau and T. Bichofberger for their kind discussions.

\section{References}

[1] Terauchi, H., Takeuchi, T., Nakatsu, K. and Maruyama, N., Japan J. Appl. Phys. 13 (1974) 1203.

[2] De Gennes, P. G., The Physics of Liquid Crystals, Claren don Press, Oxford (1974).

[3] McMillan, W. L., Phys. Rev. A 4 (1971) 1238, ibid. A 6 (1972) 936, ibid. A 7 (1973) 1673.
[4] Terauchi, H. and OhNishi, R., J. Phys. Soc. Japan 40 (1976) 915.

[5] Als-Nielsen, J., Birgeneau, R. J., Kaplan, M., Litster, J. D. and SafinYa, C. R., Phys. Rev. Lett. 39 (1977) 352. 